\title{
The Perfection Analysis of Chinese Government's Purchase of Public Sports Service System
}

\author{
Lina Zhao', Shuying Wang \\ ${ }^{1}$ College of Physical Education, Hebei Normal University, Hebei, China, 050024
}

\begin{abstract}
Keywords: Government, Intelligence Department, Purchase, Public Sports, Social Organization, Laws and Regulations
\end{abstract}

\begin{abstract}
Chinese government to buy public sports services reflects the transformation of government functions, but at the same time, this function is a change in the institutional arrangements, and is arranged in the field of public sports services within the expansion of work for domestic and foreign of the government to buy public sports services related to the practice of comparative analysis and found that the Government in the purchase of public sports services in the process of effective realization of the public sports service resources, reasonable allocation of public sports service resources to improve the utilization of public sports Service social organization has an important role in the formation, but also to achieve the government functions of the work efficiency and social image of the maintenance. From the perspective of sociology to analyze the work of the government to buy public sports services, we need to study the institutional problems existing in the purchase of public sports services by our government, and combine the legal system and social supervision requirements to buy enough public sports Service system in the imperfect part of the improvement, this article on this basis, that is, the Chinese government to buy public sports service system to improve the content of the content and related points to study and analysis.
\end{abstract}

\section{Introduction}

On the national government to buy public sports services mainly from the United States and the United States and other Western developed countries, and from the eighties of last century began to expand in different countries in the world, and China is the end of the world at the end of the introduction of such government to buy public sports services System. In the process of purchasing public sports service, the government needs the relevant duties of the relevant departments of the government to perfect and innovate the system of purchasing public sports service. In the continuous exploration and attempt, the government will summarize the methods and experiences and promote the purchase of public Sports service system is more standardized, institutionalized and unified. On the government to buy public sports services, early from Chinese economically developed regions and cities such as Beijing, Shanghai, Shenzhen and Guangzhou and other places, and gradually to the economic development of small and medium-sized cities to expand the government to buy public sports services involved Fields and scope are also expanding, mainly including cultural and educational, health care, poverty alleviation, sports, community management, disabled people help, pension benefits, social work, environmental protection and community correction and other aspects. In order to meet the needs of different social needs, the government needs to improve and supplement the institutional content of the public sports service. Under the premise of improving the government function and system supply, the government supervision and management mechanism is more comprehensive and the policy implementation is more in place. For the constraints of public sports organization and development, it is necessary to study and formulate effective problem-solving methods from the point of view of legal perfection and government management innovation so as to make the process of government's purchase of public sports service clear and perfect the supervision and evaluation system. Effectively enhance the government in the public sports services in the organization to participate in the effectiveness and 
strength.

\section{Analysis on Government to Buy Public Sports Service System}

\subsection{Policy Implementation Issues}

The government's decision on the purchase of public sports services is a normative arrangement, so the government's policy can be better implemented for the government's more standard in the design of the relevant legal system for public sports services. China from the regional to the national expansion of the government to buy public sports services, in practice, continue to promote the scope of purchase and purchase of the increase in the operation of which also have more constraints [2]. Different areas for the government to purchase public sports services have introduced policies, these policy documents for the government to buy public sports services to provide the necessary protection, but these policy documents on the purchase of public sports services, the binding conditions are mostly programmatic content, for the government The content of the purchase of public sports services directory and the system design is not detailed, the service standard system is not perfect, which led to the government's policy cannot be implemented in place, and the lack of specialized evaluation system and co-management system, affecting the overall efficiency of the implementation of the work.

\subsection{Procedural Issues}

Government to buy public sports services, not only to meet the basic needs of the public, but also to different types of social sports resources to integrate, to promote public sports services tend to social and market-oriented development, is conducive to public sports service quality and capital utilization Increased rate. However, the institutional content of the government's purchase of public sports services is not perfect, and there is no standardized requirement for the government's service purchase behavior and operation process, which will lead to the lack of regulatory mechanism and performance evaluation mechanism. Government departments to buy public sports services for public sports services and content is not clearly defined, and in the process of bidding may be due to system vulnerabilities led to the existence of personal interference and other issues, affecting the tender results [3]. The existence of the government's purchase of the public sports service system will further lead to the choice of the purchase of public sports service options are too casual, resulting in deviations from the designated purchase directory, and this will lead to the government in the purchase of public sports services in the process of existence Wrong way of buying, resulting in improper selection of noncompetitive purchases and competitive purchases.

\subsection{Social Organization Issues}

Chinese economic and economic development, economic growth and economic system have changed, so the field of public transport services in the field of resources on the basis of the original changes has taken place, and the government to buy public sports services has gradually become a trend needs to change in the traditional mode of work. Since the government is not the only provider of public sports services in a pluralistic social environment, the supply of public sports services should also change. With the government to expand the field of public sports services involved in the expansion of the management system is not perfect and comprehensive circumstances, some sports organizations there are a variety of "difficult to register", "to undertake difficult", "difficult" and "difficult development" The problem of the settlement of these problems, the need to make the internal management mechanism and external development environment to adapt to the government to buy public sports service system, the system is not perfect, will lead to public sports service supply system innovation, reform is not enough, affecting society Further development of sports organizations [4]. 


\section{The Improvement Measures and Strategies of Government to Buy Public Sports Service System}

\subsection{Innovative Management}

In the process of purchasing public sports service, the government needs to fully realize its own functional utility and it must be clearly defined for its own scope of work and responsibilities, and lay the foundation for the innovation of government management. According to the basic situation of our country, it is necessary to focus on the administrative characteristics of public sports service management in the practice of government purchase of public sports service. The government has a high degree of dominance and autonomy for public sports service resource management Right, in order to reduce and prevent the government offside, absence and other issues [5]. To achieve the management of innovation, requiring the government to recognize the role of the market, in the management capacity and management system to reform and improve, to form the market, government and society between the complementary relationship between the symbiotic relationship between the holistic work for this form As well as the system of the system, to the government to buy public sports services play a normative role in the public sports service system and the rule of law system to form a new management model.

\subsection{Combine with the Legal System}

The government in the purchase of public sports services, for the purchase of catalogs, purchase forms and purchase requirements are required to be unified, standardized provisions, in the process, you can focus on Chinese "tender and tender law" and "government procurement law" The public sports service purchase system to be supplemented by the perfect. In this process, due to different regions and provinces and cities of different levels of economic development, people for the public sports service market demand is different, so in the management system and system improvement, the need to be based on the local sports, economic development status, combined with the law Regulations, to develop a more reasonable, reliable and applicable local laws and regulations [6]. This is mainly to the government to buy public sports services to conduct the supervision and management of the operation, to reduce and prevent the rights of rent-seeking and other issues, for the purchase of public sports services content and standards, the need for detailed management system in the purchase of public The basic scope of sports services, the responsibility of the relevant government departments to be clear.

\subsection{The Establishment of a Sound Evaluation, Supervision Mechanism}

In the practice of purchasing public sports service, the government needs to realize that the purchase of public sports service is to provide the basic sports service demand for the public. At the same time, it is necessary to improve the integration and utilization efficiency of public sports service resources on the basis of government intelligence. However, before the purchase of public sports services, the government needs to conduct market research, the basic public sports services needs of the public content and standards to understand, so as to provide the government to buy public sports services to provide reference direction, the government only know "why buy" "What to buy" to improve work efficiency [7]. In this process, we can establish a sound evaluation and supervision mechanism, the government to purchase services in the process and order to be clearly defined in the evaluation of the supervision mechanism, not only to understand the public into the needs and views, but also to improve the work of government departments Form to provide advice, so that the work efficiency continues to improve, so that work behavior more standardized and reasonable.

\subsection{Performance Management}

For the government to buy public sports service work, in the early practice survey, the market demand is generally the investigation and analysis of the situation, different social organizations and public groups to purchase the price of public sports services, catalogs, etc., the government 
needs to develop a sound price list, capital budget, in the publicity and investigation, to encourage you to more public organizations to participate in bidding, so that the purchase of public sports services more in line with people's actual needs. However, in the implementation of the whole work, the relevant government departments need to maintain contact with the social organization or the public and communication, the implementation of the work to make a comprehensive performance evaluation, understanding of public satisfaction [8]. Improve the government to buy public sports service system, on the performance appraisal and evaluation is one of the important content, the buyer is the government, so in the implementation of the project process, the need for the necessary supervision and control, whether the project implementation efficiency, the implementation of the results , or the capital budget, the level of service, need to have a complete performance appraisal and evaluation system for the government to buy public sports services to provide the necessary supervision and norms.

\section{Conclusion}

The continuous development of Chinese socialist market economy has promoted the construction of urbanization and the acceleration of urbanization. At the same time, the level of regional economic development has been improved and people's awareness of rights has been strengthened. The basic demand for public services has also increased greatly. As a result of the work in the practice of public service supply capacity level is limited, thus forming a regional social public service demand supply contradiction. To better solve this contradictory problem, the relevant government departments need to actively explore the effective way to purchase public sports services and ways to buy the public sports services mainly involved in the face of public sports events, youth health services, sports training services, Site facilities construction and management and fitness services, etc., on these, through the form of government purchases, to achieve the public sports management innovation, both to meet people's public sports service needs, but also improve the utilization of public sports service resources [9 ]. The government in the process of purchasing public sports services is an outsourced form of social public services market behavior, in the process, for the purchase of services and regulatory system issues, the need for a reasonable analysis of the government to buy public sports Service operation transparency issues, financial burden, operational behavior norms and cost and efficiency issues, are required in accordance with relevant laws and regulations and systems, in accordance with the "fees" and "open", "merit" on the basis of the principle, the introduction of a certain competition and regulatory mechanism to enable the government to buy public sports services to enhance the social forces, the Government to buy public sports services, service functions, efficiency and quality of service and other aspects play a catalytic role in the government to buy public sports services System to establish a more perfect, more effective implementation.

\section{Acknowledgements}

Fund Project: Project Level: Office Level Name: 2017 Hebei Province Sports Science and Technology Research Project Number: 20172007

\section{References}

[1] Zhong Xi Ting, Yang Jinbo, Zhang Bing. Local government to buy public sports service effectiveness, problems and optimization path - to Yuanbaoshan Sports Park as an example[J]. Hubei Sports Science and Technology, 2016,35 (12): 1039-1041 +1102.

[2] Cong Huoping, Lu Wei. The Mode, Problems and Suggestions of Government to Purchase Public Sports Service - Based on the Survey of Provinces of Jiangsu, Zhejiang, Shanghai and Guangdong[J]. Journal of Sports Science, 2016,36 (12): 11- 17.

[3] Shen Keyin, Lu Wanchang. (School of Physical Education, Chengdu University of Technology, 
Chengdu 610031, China); Research on the System Construction of Public Sports Service in China[J]. Journal of Chengdu Sport University, 2017,43 (01): 37-42 + 49. 2017-02-16)

[4] Wu Sa. Government to buy public sports service performance evaluation status - based on the experience of Shanghai and Changzhou [J]. Beijing Sport University, 2017, 40 (03): 11-15.

[5] Guo Xiujin, Dai Jian. The practice, problems and measures of the government to buy sports social organization public sports service - Taking Shanghai and Guangdong provinces as an example [J]. Journal of Shanghai Institute of Physical Education, 2014, 38 (03): 74-7 (1): 1. 12.

[6] Wang Zhankun, $\mathrm{Wu}$ Lanhua, Zhang Xiancheng. The effectiveness, dilemma and countermeasure of local government 's purchase of public sports service [J]. Journal of Tianjin Physical Education Institute, 2014, 29 (05): 409-414.

[7] Zhan Xingyong. The International Experience of Government's Purchase of Public Sports Service and the Way to Promote Chinese [J]. Journal of Shandong Institute of Physical Education, 2015, 31 (01): 14-18

[8] Mei Xiangping, Guo Jianqiang. Study on the Performance of Government to Buy Public Sports Service - Taking Changzhou City as an Example [J]. Sport Science and Technology, 2017,03: 88-89. (2017-09-03)

[9] Shen Keyin, Chen Yinqiao, Yang Yiran. Government to the sports social organizations to buy public sports services: logic, difficulties and governance strategies [J]. Sports Adult Education Journal, 2016,32 (01): 39-43 + $49+2$ 